\title{
VIOLÊNCIA, GÊNERO E ADOÇÃO
}

Veralúcia Pinheiro*

\section{RESUMO}

Propõe-se, no presente artigo, discutir questões relacionadas à educação familiar, violência e adoção, a partir da experiência de Patrícia, uma menina que, por várias vezes, foi "adotada" e devolvida às instituições sociais que abrigam crianças abandonadas. Essa condição de mercantilização do sujeito e sua transformação em objeto é discutida a partir da interlocução com os autores que se debruçaram sobre estudos e pesquisas para compreender questões como valores, violência e cultura. Assim, as diversas concepções de educação, violência e vida familiar são problematizadas, e o aparente consenso em torno da adoção no Brasil, amplamente divulgado como a melhor forma de solucionar a questão do abandono social, econômico e afetivo em que se encontra significativo número de crianças, é abordado na perspectiva de evidenciar o lado que permanece oculto na sociedade contemporânea.

Palavras-chave: educação familiar, cultura, gênero, adoção e violência.

\section{INTRODUÇÃO}

Este trabalho discute algumas questões sobre abandono de crianças, adoção, violência sexual e gênero, uma vez que os problemas discutidos dizem respeito às condições de vida de uma menina. As reflexões a serem desenvolvidas surgiram a partir de pesquisa

\footnotetext{
*Doutoranda na Faculdade de Educação da Unicamp e professora convidada da Universidade Católica de Goiás e da Universidade Estadual de Goiás (UEG). [e-mail: verinhapinheiro@hotmail.com]
} 
realizada com nove meninas vítimas de abuso sexual na família, com a finalidade de elaboração de uma dissertação de mestrado. ${ }^{1}$ Este artigo baseia-se no estudo de apenas um caso, cujos relatos vão expor a experiência de Patrícia, ${ }^{2}$ uma história singular, porém capaz de recriar as condições de muitas outras meninas que, abandonadas por suas famílias, alimentam-se da esperança da adoção, mesmo que na ótica da estranha categoria "família substituta", criada pelo Estatuto da Criança e do Adolescente (ECA). Essa categoria, muitas vezes, substitui a violência pela violência e não cumpre a "promessa" amplamente divulgada e aceita pela sociedade que vê a família como "refúgio" contra as dificuldades de um mundo frio e cruel, enfim, a família substituta é a alternativa legal intermediária entre a adoção e a institucionalização. Uma família pode, a título de experiência, abrigar em sua casa criança ou adolescente antes de se decidir pelo processo definitivo de adoção.

A adoção de crianças pobres por famílias "bem intencionadas" é um hábito cultivado na sociedade brasileira que data de tempos remotos e muitas vezes ocorre à revelia da lei. A ideologia da família como um lugar seguro, ideal para o desenvolvimento saudável, livre das más influências da rua, portanto o melhor lugar para viver e sobreviver, certamente colaborou para que o ECA, mesmo com sua característica de lei progressista, mantivesse em seu texto a referida categoria "família substituta".

Fonseca (1997, p. 536) discute a precariedade das famílias dos grupos populares no Brasil e afirma que, para garantir a sobrevivência das crianças, estudos antropológicos e dados etnográficos têm apontado para a natureza aberta da unidade doméstica. Dessa forma, uma viagem ao interior para assistir a alguma festa simbólica poderia virar uma estada de anos, dependendo da conveniência para o adulto ou até mesmo do desejo da criança. Além disso, situações de migração, divórcio e morte foram, historicamente, causa comum de ruptura das famílias populares. Muitas decisões envolvendo crianças - criá-las, escolarizá-las - e seu destino após a separação ou morte dos pais não são de maneira alguma restritas ao núcleo familiar. É também muito comum os filhos mais velhos se 
responsabilizarem pela criação dos irmãos mais novos. No caso de Patrícia, há evidências desse mesmo tipo de dinâmica.

Selecionada para participar da entrevista, em momento algum Patrícia procurou dificultar sua realização. Ao contrário, dispôs-se a falar de sua vida atual e de seu passado como quem procura dividir com o interlocutor suas mágoas e esperanças. Inicialmente, contou que nasceu na cidade de Marabá, no estado do Pará, e que está com 16 anos. Veio para Goiânia com seis anos e mora no Abrigo Amor Perfeito. Freqüenta a 5a série do ensino fundamental em uma escola pública. No abrigo, cuida da horta e ganha uma bolsa no valor de $1 / 3$ do salário mínimo. Sofreu abusos sexuais cometidos pelo irmão adulto quando tinha seis anos de idade e, depois disso, sua vida mudou completamente.

Suas lembranças da infância são confusas. Ao mesmo tempo em que se recorda de um tempo bom, quando tudo era "normal" e não apanhava dos pais, não consegue lembrar-se da educação que recebeu em casa, repete apenas que não lembra nada, apenas da irmã que lhe deu cigarro e bebida. Depois, referindo-se ao abrigo, Patrícia lamenta a família que não teve:

A educação que eu tive não foi boa não, porque eu não fiquei com eles, quem me deu educação foi abrigos... aprendi tudo em abrigo - mexer com droga, beber, fumar, tudo em abrigos.

A família e o abrigo representam a mesma coisa, ou seja, a introdução ao mundo dos vícios, embora algumas vezes, paradoxalmente, tente negar a precariedade de sua família. As contradições de sua narrativa expressam a confusão que tem sido sua vida depois que ela saiu de casa ou depois que sua mãe abandonou a família. Quando fala dos sentimentos familiares, deixa transparecer mágoa e ambigüidade, pois em sua casa, com exceção do abuso sexual cometido pelo irmão adulto, não sofreu nenhum outro tipo de violência. Entretanto, depois de abandonada, suportou as inúmeras violências que se iniciaram a partir do momento em que foi doada a terceiros pela irmã mais velha (adulta): 
[...] Foi na festa [...] do Divino, que eu adoro esse santo. Fui eu, meu cunhado, minha irmã [...]. Aí a gente parou para almoçar na casa de uma mulher e a mulher falou que me achou muito bonita e pediu minha irmã... falou assim: - Me dá sua irmã... E ela foi e deu. Fui dada para os outros. Fiquei dois anos com a mulher [...] e ela me batia demais...

Patrícia lembra ainda que antes de tudo isso acontecer sua mãe já havia abandonado filhos e marido:

Minha mãe abandonou a gente e foi morar com a mãe dela, porque ela foi abandonada pela mãe, e depois a mãe foi buscá-la e então ela deixou os filhos. Meu pai ficou cuidando de todo mundo. E aí meu pai me deixou com minha irmã, porque eu era pequena, não dava para ficar lá só com homem, morando com homem [...] não dava certo. Daí minha irmã me deu para essa mulher, e ela me batia demais. Por isso meu pai adotivo chegou lá e viu e me tomou dela e a gente fugiu para Goiânia e ele me deixou com a mãe dele. A mãe dele fez a mesma coisa: me deu para os outros [...] deu para uma família. Aí não combinamos, porque eu ficava muito com o marido da mulher, porque eu era muito infantil, gostava muito de livros e ele lia para mim e a mulher não gostou [...] Aí, ela me devolveu [...] para minha avó.

O pai adotivo de Patrícia, a quem ela se refere como um possível protetor, era o namorado da mulher que a espancava e para a qual foi doada pela irmã na festa do Divino. Esse pai adotivo trouxe-a para Goiânia, procurando protegê-la da violência da primeira mãe adotiva e deixou-a com a própria mãe, a quem a menina chamava de avó, e que também resolveu doá-la para outra família que, por sua vez, aplicava-lhe surras, como se pode observar na continuidade de sua narração:

[...] Minha avó foi lá na frente de novo, da igreja e me doou para outra mulher. Morei com ela um bom tempo. Ela me batia demais, ela bebia, era alcoólatra [...]. Eu fazia muita arte, aí eu fugi dela simplesmente [...], não estava suportando mais apanhar. Eu estava com nove anos de idade quando eu fugi dela por aí, sem rumo [...], 
perto do Rio Vermelho [...]. Aí o policial me pegou no caminho, me devolveu para ela e ela, no outro dia, me levou para o Juizado, arrumou um psicólogo para mim. Eu tornei a fugir porque ela me batia... Ai ela me devolveu para o Juizado, e eu fui morar no Abrigo "Lar das Crianças Pai Joaquim". Eu fui com 10 anos morar lá... Morei de 10 anos até... Foi só um ano. Fui para outro lugar... Condomínio Sol Nascente, com 11 anos, e fiquei lá três anos e saí para a rua. Meu destino era a rua.

As piores lembranças da menina estão relacionadas justamente às famílias substitutas. Com exceção de sua segunda mãe adotiva, cujo problema foi o ciúme do marido, as demais estabeleceram com ela um relacionamento baseado prioritariamente na violência física. As concepções da irmã que inauguraram o processo de sua doação e as da avó (adotiva), que doou a menina para uma mulher e depois para outra, chegando a apresentá-la na igreja como pessoa disponível para quem quisesse levá-la para casa, demonstram que, a par do conceito moderno de criança desenvolvido a partir do século XVIII, a sociedade atual, além de manter resquícios de um passado que não respeitava as crianças em suas especificidades, ainda mantém a mercantilização das relações. Nesse caso, as famílias que se interessaram por Patrícia fizeram-no pela possibilidade de obter serviços domésticos gratuitos, e não para protegê-la e amá-la como filha. Também para a irmã e avó adotiva, a criança foi um objeto, uma mercadoria.

Convencionalmente tomada como locus de proteção e de inculcação de normas, regras e valores, a família ocupa papel central entre as instituições que possuem papel similar, mas as diversas formas de autoritarismo e violência em seu interior indicam que nem sempre esse núcleo pode ser considerado de forma homogênea. Desse modo, é necessário analisá-lo enquanto espaço de diversidade e de contradições, cujas origens encontram-se em processos inerentes à formação e à organização da sociedade. Sendo assim, atitudes como o abandono das crianças ou a sua mercantilização, a utilização de surras e outros castigos devem ser compreendidas como conseqüência de pressões advindas das condições materiais de vida ou provenientes da base cultural autoritária em que se formou a família brasileira. 
Falar sobre afetos e carinhos significa para Patrícia trazer novamente as lembranças da família que a abandonou quando ainda era muito pequena:

Se isso não tivesse acontecido, se minha família não tivesse me dado para os outros, eu seria mais feliz ao lado dos meus pais. Agora eu sofro não só por causa de quem eu quero namorar, mas por falta da minha família. Mas eu não vou atrás, de forma alguma. Se algum dia minha mãe vier atrás de mim, eu falo para ela voltar pelo mesmo caminho que ela veio, porque eu não aceito aquela mulher [...].

Para Bosi (1994, p. 423), as lembranças do grupo familiar persistem sob diferentes matizes em cada indivíduo e constituem uma memória que é, ao mesmo tempo, una e diferenciada. As experiências vividas na infância guardam vínculos e recordações difíceis de apagar. Assim, mesmo com a desagregação do núcleo onde a história teve origem, os vínculos podem permanecer, demonstrando, por outro lado, que esse enraizamento num solo comum transcende o sentimento individual. Em nenhum outro espaço social o lugar do indivíduo é tão fortemente destinado quanto na família. Ele pode sempre mudar sua condição social, deixar de ser brasileiro, naturalizando-se em outro país, deixar de ser solteiro, casando-se ou vice-versa, mas o vínculo que o ata a sua família é irreversível. A força de coesão da família reside no fato de que ela representa a mais importante mediação entre a criança e o mundo.

Concordar com a perspectiva de Bosi é considerar que os efeitos do abuso sexual na infância podem ou não prejudicar quem passou por essa experiência como vítima, só não é possível considerála totalmente indiferente. Azevedo e Guerra (1993, p. 198) consultaram a literatura sobre as consequiências do abuso sexual para as vítimas e verificaram que há duas posições básicas: a que admite a possibilidade de conseqüências negativas e a que não defende essa possibilidade. Para a primeira, as consequiências são a curto e a longo prazo. A segunda compreende que os problemas das crianças envolvidas em abusos sexuais estão vinculados à revelação dos fatos e não ao fato em si. Ainda de acordo com a segunda posição, as relações sexuais 
entre adulto e crianças podem perfeitamente ser saudáveis, desde que baseadas no consentimento. Somente quando há extrema coerção e violência física pode-se falar em consequiências negativas.

Segundo as autoras, as duas posições ignoram uma questão fundamental, que é a do poder adulto-criança. Portanto, pressupõese que as vítimas infantis de abuso sexual são mais vulneráveis aos danos decorrentes da violência, mas não se pode concluir que, inevitavelmente, sofrerão danos permanentes.

Ao falar de sua vida afetiva no presente, Patrícia busca no passado explicações para as dificuldades que a afligem. Ela não relaciona seus problemas afetivos ao abuso sexual que sofreu aos seis anos, mas, sim, ao abandono ocorrido logo após:

Dependendo do lugar, eu fico bem. Agora que estou no Projeto, estou melhor, apesar de que o pessoal me irrita muito, porque tem umas meninas que eu não gosto [...] porque elas levam os namorados. Daí eu falo para a tia: - Vou trazer minha namorada. E ela responde: - Não vai trazer não, o que é isso? Eu falo: - Se as meninas trazem por que é que eu não posso? [...] Dia 30 de junho, a tia viu a gente se agarrando, chegou em mim e falou assim: Você não vai apresentar sua namorada para nós? Respondi: Não, pra quê? Vocês não estão nem a favor nem contra, ficam no meio, não sabem de nada [...]. Olha, a gente sofre muito, escolhe uma pessoa e ela não dá a mínima [...]. Se isso não tivesse acontecido, minha família me abandonar, eu seria mais feliz. Ao lado dos meus pais era melhor, porque agora eu sofro não só por causa de quem eu quero namorar, mas também por falta da minha família, dos meus sobrinhos. Mas eu não vou atrás, se minha mãe vier atrás de mim, falo para ela voltar pelo mesmo caminho que ela veio. Eu não aceito aquela mulher [...], porque assim o que eu vi ela fazendo eu não gostava. Ela vivia no puteiro, isso não é coisa que se faz. Já imaginou se fosse agora que cresci pegar o exemplo dela e ir para o puteiro? [...]. Ela foi muito covarde em me abandonar. Eu gosto dela, mas não tem perdão [...] eu não aceito ela. Agora meu pai eu aceito.

A experiência de Patrícia, certamente semelhante à de outras meninas, revela a violência escondida no interior das instituições 
sociais, protegida pelo silêncio e por uma banalização caracterizada por Costa (1986, p. 34) como os aliados mais fortes de sua perpetuação. Pois resignado à idéia inculcada pela repetição do jargão de que somos "instintivamente violentos", o homem curva-se ao destino e acaba por admitir a existência da violência como admite a certeza da morte.

Nesse sentido, é possível perceber a violência como um fenômeno amplo que envolve dimensões históricas, sociais, culturais e que se apresenta de diferentes formas. Costa (1986, p. 24), por exemplo, divide a violência em duas modalidades: a primeira referese a uma violência racional, na qual o ato é dirigido a um objeto adequado; a segunda trata de uma violência irracional e, nesse caso, o ato é dirigido a um objeto substitutivo. Em toda violência, há um desejo de destruição que dirige a ação agressiva e, por isso, a violência não é fruto do instinto; mesmo quando irracional, sua origem é sempre centrada na razão e não na manifestação desordenada do instinto. Nesse sentido, ela pode ser arbitrária e deslocada, mas não é substituída. Para Chauí (1982, p. 24), a violência existe quando um indivíduo ou uma instituição, através de meios físicos ou psíquicos, impede a manifestação de outro indivíduo na sua singularidade. Violência, portanto, implica a negação de um sujeito pelo outro, ou seja, a restrição à manifestação da subjetividade inerente a cada indivíduo. Ao colocar a violência no espaço da subjetividade, Chauí divide-a com as relações autoritárias, cujas manifestações estão nitidamente presentes quando se desrespeita a diversidade, uma característica essencial da pessoa humana, e que se apresenta na sociedade como fonte de discriminação.

Do ponto de vista histórico e coletivo, o capitalismo e a violência estão intrinsecamente ligados e se criam e se recriam nas suas configurações modernas. O desenvolvimento do capitalismo pressupôs inúmeras formas de violência, como o fascismo e o nazismo. Para Hobsbawm (1995, p. 56), o século XX apresentou-se como o mais violento da história da humanidade, com o seu caráter definido pelas duas grandes guerras. Foi a partir da Primeira Guerra Mundial que se rompeu um antigo acordo celebrado pelos Estados modernos, pelo qual os países comprometiam-se a não realizar ataques sem aviso e, na medida do possível, limitar-se à incapacitação das forças armadas. 
Porém, após 1914, as guerras foram travadas contra a economia e a infra-estrutura dos Estados e suas populações civis. Além disso, os Estados modernos fizeram ressurgir a tortura e o assassinato como parte normal das operações de segurança pública, embora, do ponto de vista jurídico, a tortura já tivesse sido abolida desde 1880.

Em relação ao aumento da brutalização, o autor argumenta que ela não se deveu somente à liberação do potencial latente de crueldade que a guerra naturalmente legitima, mas que houve um outro importante motivo: a sua estranha democratização. Os conflitos transformaram-se em "guerras populares", porque os civis e a vida cotidiana tornaram-se os alvos estratégicos principais e porque, em guerras democráticas, os adversários são demonizados para se tornarem devidamente odiosos ou, pelo menos, desprezíveis.

A mobilização dos sentimentos nacionais de massa rompeu com as leis e a ética que regiam a violência das guerras no passado. Na Segunda Guerra Mundial, além dessa demonização das massas que justificou os massacres, houve a impessoalidade garantida pela tecnologia. Assim, as maiores crueldades desse século foram impessoais, decididas a distância, e ficaram conhecidas por genocídios. Essa impessoalidade, somada à eficiência dos novos armamentos, diversificou e tornou a violência um fenômeno ainda mais complexo na realidade do mundo contemporâneo.

Embora não seja nova, a violência assume formas antes desconhecidas, torna-se requintada, rotineira, banalizada e, muitas vezes, aceita e legitimada por uma cultura que, na verdade, cultua-a e justifica-a. Com significados históricos e políticos diferenciados, a violência possui raízes profundas.

Arendt (1985, p. 27) critica a explicação da violência que enfatiza o aspecto econômico e a vincula ao caráter instrumental da tecnologia, separando-a do exercício do poder e relacionando-a com a perda da legitimidade. A autora analisa as contradições enquanto processo histórico amplo e defende que a emergência de uma sociedade está menos vinculada à violência do que aos desgastes e ao esgotamento das condições da antiga sociedade.

Para Arendt (1985, p. 29), a violência manifesta-se quando o poder está em processo de deterioração, perdendo sua legitimidade. 
Poder e violência, mesmo distintos, apresentam-se interligados. O terror é utilizado para dirigir e dominar quando o poder já se encontra destruído, sem legitimidade, e o indivíduo ou o grupo não renuncia, mas prossegue diante de sua própria falência. Sua eficácia depende, em grande parte, do grau de atomização social e, nesse sentido, a violência não possui um caráter individual, ao contrário, está presente nas relações sociais e políticas.

Horkheimer (1990, p. 178) também chama a atenção para a importância da cultura, sem esquecer os aspectos relacionados à produção e à reprodução da vida material. Para ele, o modo de agir dos homens nem sempre pode ser explicado apenas pelos processos econômicos que ocorreram no momento imediatamente anterior. Os grupos agem sempre com base no caráter típico de seus membros, cuja formação ocorreu em conexão tanto com a evolução social anterior quanto com a atual. Esse caráter origina-se da atuação da totalidade das instituições sociais que funcionam de maneira específica para cada camada social. A produção material da vida influencia os homens não só de maneira direta, em seu próprio trabalho, mas também na forma como eles se situam dentro das instituições relativamente fixas, ou seja, daquelas que se transformam muito lentamente, como a família, a escola, a igreja, as instituições de arte. Portanto, para compreender o caráter estável de uma sociedade ou sua tendência à desagregação, é preciso conhecer a respectiva constituição psíquica dos homens nos diversos grupos sociais, a formação de seu caráter e suas conexões com todas as forças culturais da época.

Horkheimer (1990, p. 181) argumenta ainda que a predisposição a impulsos, característica própria dos membros de uma determinada sociedade de acordo com seu vínculo a grupos específicos, nem sempre seria determinante da manutenção de processos ultrapassados de produção e da solidez do edifício social neles baseado, mas isso decidiria, conforme a disponibilidade econômica, a arte de governar, a organização do poder do Estado, bem como a força física. Pois, na história de todas as culturas, o fruto dos conhecimentos e das aptidões humanos e o aparelho material de produção foram constituídos de tal forma que o processo social de vida desenvolveu-se somente a partir 
da clássica divisão entre quem executa e quem dirige. A necessidade dessa divisão para a sobrevivência do conjunto da população, pelo menos em época de ascensão e de apogeu, não significou harmonia na convivência entre a minoria detentora do poder e a maioria submetida à miséria. Ao contrário, a manutenção dos homens dentro de formas desiguais e opressivas nunca ocorreu sem violência. Por isso, para o autor, nem é preciso afirmar um conceito dinâmico de cultura que pressuponha uma argamassa espiritual da sociedade, uma vez que essa argamassa está presente, antes, na forma altamente material do poder executivo nacional.

$\mathrm{O}$ autor descarta as teorias que, em sua compreensão, convertem a natureza humana, a consciência ou a razão, as idéias morais e religiosas em realidades firmes e independentes e tentam explicar o funcionamento da sociedade pela atuação de uma ou mais dessas realidades. Para ele, essas idéias estão ligadas aos poderes na sociedade e não são, de forma alguma, secundárias, além de que o aparelho psíquico dos membros de uma sociedade de classes, a não ser que pertençam àquele núcleo de privilegiados, constitui, em larga escala, apenas a interiorização ou, pelo menos, a racionalização e complementação da violência física. A integração em determinada ordem e a chamada natureza social, a par das justificativas morais e religiosas, são internalizadas pelos indivíduos através da coação. A sociabilidade dos homens e a garantia da observação nas regras de convívio são descritas também por Nietzsche e citadas por Horkheimer (1990, p. 181) como relações marcadas pela violência:

Marca-se algo com fogo, para que fique na memória: somente o que não cessa de doer permanece na memória - é esta uma sentença da mais antiga (infelizmente também mais longa) psicologia na terra. Sentimo-nos tentados a dizer que, em todo lugar onde ainda existem solenidade, seriedade, mistério, cores sombrias na vida do homem e do povo, persiste algo de horror com que antigamente, em todo mundo, se prometeu, se empenhou, se louvou: o passado... nos bafeja e brota em nós, quando nos tornamos "sérios". Nunca ficou sem sangue, torturas e sacrifícios e oferendas mais repulsivos (entre os quais se incluem os sacrifícios dos primogênitos), as mutilações mais repugnantes 
(por exemplo, as castrações), as formas rituais mais cruéis de todos os cultos religiosos (e todas as religiões, na sua base mais profunda, são sistemas de atrocidades) - tudo isso tem sua origem naquele instinto que adivinha na dor o mais poderoso auxiliar da mnemônica... Ah! razão, a seriedade, o domínio sobre os afetos, toda esta coisa lúgubre que se chama pensar, todos estes privilégios e faustos do homem: quão caro eles se fizeram pagar! Quanto sangue e horror estão na base de todas as "coisas boas".

Dessa forma, toda a evolução política e social da humanidade é mediada pela coação, influenciando as diversas manifestações da natureza humana. Sua presença pode ser percebida não somente nas punições, mas em qualquer forma de submissão, inclusive naquelas que ocorrem em função do medo do desemprego, da fome, da falta de moradia etc. A perspectiva de abandono material é um poderoso mecanismo de sujeição dos indivíduos à ordem estabelecida, pois, mesmo quando se encontram ausentes formas de crueldade explícita, essa ameaça exerce o papel de mantenedor da ordem.

À preocupação de Arendt (1985, p. 27) de desvincular o aspecto econômico do exercício do poder e sua decadência que geralmente desemboca na violência, devem-se acrescentar as contribuições de Horkheimer acerca dos aspectos culturais adquiridos a partir da produção e da reprodução da vida social. Tanto essa decadência que desemboca na violência citada por Arendt quanto os aspectos culturais enfatizados por Horkheimer influenciam o modo de pensar e agir do indivíduo, não apenas no exercício de suas atividades laborais, mas também quando exerce o papel de pai, mãe, professor, líder religioso, no interior das instituições. Portanto, a violência, além de ser uma prática racional, pode tornar-se uma maneira de agir de indivíduos ou grupos de qualquer classe social, raça ou religião.

Entretanto, a violência sexual contra a criança e o adolescente no interior da família parece ser a que provoca maiores inquietações no contexto da sociedade contemporânea, pois sua existência desmistifica a crença numa sociedade que superou a barbárie e garantiu a humanização nas relações.

Adorno (1995, p. 305) situa a família como espaço perigoso para as crianças, lembrando a intervenção agressiva dos pais a fim 
de corrigir o comportamento, eliminar condutas indesejadas e obter sua submissão, enquanto as instituições e autoridades fecham os olhos para a intensidade e a regularidade com que tais reprimendas são praticadas.

Mas a violência - ou o abuso sexual contra a criança e o adolescente - apresenta-se como um problema universal e transversal, que vai além das fronteiras de classe, culturais, geográficas, raciais e religiosas. Particularmente, em relação a Patrícia, tratou-se de violência contra a menina-mulher, uma violência também de gênero, muitas vezes aceita como prática que apresenta um certo grau de legitimidade no imaginário social. Bandeira (1999, p. 362), ao discutir a questão de gênero, alerta para essa legitimidade dos homens, que os leva a se "auto-atribuírem" liberdade e autonomia na configuração de suas relações sexuais com as mulheres. Para ela, basta observar as relações interpessoais, as estruturas mentais manifestas através dos códigos culturais que produzem sentidos, legitimam e naturalizam o fato de os homens exercerem sua sexualidade mediante a dominação, o controle e a imposição de hábitos, vícios e comportamentos sexuais às esposas ou às namoradas.

Nesse sentido, como lembra Saffioti (1997, p. 167), o caminho para uma sociedade não violenta com relação ao gênero considerado socialmente inferior e à geração imatura consiste numa transformação radical das relações sociais. É preciso, pois, modificar a gramática sexual que rege essas relações, não apenas do ponto de vista formal, mas através do envolvimento de práticas sociais e políticas cotidianas que incluam, necessariamente, as concepções educativas.

\section{ABSTRACT}

The purpose of the present article is to discuss subjects related to family education, violence and adoption, through the experience of Patricia, a girl who, for many times, was "adopted" but was given back to Social Institutions that take care of abandoned children. This condition of transforming the subject in an object, treated as part of the market system is discussed based on the dialogue with authors that have been working on researches in order to understand subjects such as values, violence and culture. So, the diversity 
of the concepts of education, violence and family life are put in doubt and the apparently consensus around the issue "adoption" in Brazil, considered in large scale the best way to solve the problem of social, economic and affective abandoned of children is approached from a perspective to evidence the covered side of our contemporary society.

Key words: family education, culture, adoption, violence, gender.

\section{NOTAS}

1. Dissertação realizada sob orientação da profa. dra. Anita C. Azevedo Rezende.

2. Nome fictício.

\section{REFERÊNCIAS}

ADORNO, S. A violência na sociedade brasileira: um painel inconcluso em uma democracia não consolidada. In: Sociedade e Estado. Brasília: Editora da UnB, v. 10, n. 2, jan.- dez., 1995.

ARENDT, H. A condição humana. Trad. Roberto Raposo. 7. ed. Rio de Janeiro: Forense Universitária, 1995.

AZEVEDO, M. A. Notas para uma teoria crítica da violência familiar contra crianças e adolescentes. In: AZEVEDO, M. A.; GUERRA, V. N. de A. Infância e violência doméstica: fronteiras do conhecimento. São Paulo: Cortez, 1993.

BANDEIRA, L. Violência sexual, imaginário de gênero e narcismo. In: SUÁREZ, M.; BANDEIRA, L. (Orgs.) et al. Violência, gênero e crime no Distrito Federal. Brasília: Paralelo 15 / Editora da UnB, 1999.

BOSI, E. Memória e sociedade: lembranças de velhos. 7. ed. São Paulo: Companhia das Letras, 1994.

CHAUÍ, M. Cultura e democracia. São Paulo: Editora Moderna, 1982.

COSTA, J. F. Violência e psicanálise. 2. ed. Rio de Janeiro: Graal, 1986.

FONSECA, C. Ser mulher, mãe e pobre. In: DEL PRIORE, M. (Org.). 2. ed. História das mulheres no Brasil. São Paulo: Contexto, 1997.

HOBSBAWM, E. Era dos extremos: o breve século XX. 1914-1991. Trad. Marcos Santarrita. São Paulo: Companhia das Letras, 1995. 
HORKHEIMER, M. Teoria crítica. Trad. Hilde Conh. São Paulo: Perspectiva, 1990.

SAFFIOTI, H. I. B. No fio da navalha. Violência contra crianças e adolescentes no Brasil atual. In: MADEIRA, F. R. (Org.). Quem mandou nascer mulher? Estudos sobre crianças e adolescentes pobres no Brasil. Rio de Janeiro: Record/Rosa dos Tempos, 1997.

RECEBIDO EM 06/01/2003

AProvado EM 12/05/2003 